\title{
Effect of Tissue Factor on Colorectal Cancer Stem Cells
}

\author{
HAMISH WILLIAM CLOUSTON ${ }^{1,2}$, PETER ADAM REES ${ }^{1,2}$, REBECCA LAMB ${ }^{1}$, \\ SARAH ELIZABETH DUFF ${ }^{2}$ and CLIONA CLARE KIRWAN ${ }^{1,2}$ \\ ${ }^{1}$ Institute of Cancer Sciences, The University of Manchester, Manchester, U.K.; \\ ${ }^{2}$ Manchester University NHS Foundation Trust, Manchester, U.K.
}

\begin{abstract}
Background/Aim: Tissue factor (TF) expression increases cancer stem cell (CSC) activity in breast and lung cancer. There are ongoing studies focused on targeting CSCs via anti-TF treatment, for breast and lung cancer therapy. Herein, the aim was to determine whether targeting TF could have an anti-CSC therapeutic role in colorectal cancer (CRC). Materials and Methods: Evaluation of colonosphere-forming efficiency (CFE) and aldehyde dehydrogenase (ALDH) expression level was used to quantify CSC activity in two CRC cell lines, after TF knockdown (TFKD) or TF over-expression (TFOE). Results: TFKD resulted in increased levels of ALDH in SW620 (1.31 \pm 0.04 -fold, $p<0.001)$ and DLD-1 $(1.63 \pm 0.14$ fold, $p=0.04)$ cells. CFE was increased in SW620 $(1.21 \pm 0.23 \%$ vs. $2.03 \pm 0.29 \%, p=0.01)$ and $D L D-1 \quad(0.41 \pm 0.12 \%$ vs. $0.68 \pm 0.9 \%, p=0.01)$ cells. Conversely, TFOE decreased ALDH expression $(0.72 \pm 0.04$-fold, $p=0.001)$ and CFE $(0.33 \pm 0.05 \%$ vs. $0.66 \pm 0.14 \%, p=0.006)$ in $D L D-1$, but had no impact on SW620 cells. Conclusion: In the examined CRC cell lines, TF expression was inversely related to CSC activity suggesting that anti-TF therapies may not have a role in CRC treatment.
\end{abstract}

Colorectal cancer (CRC) is the third most common cancer in the United Kingdom (UK), after cancer of the breast and prostate, with 40,755 new diagnoses in 2012 (1). It causes 10\% of all cancer deaths, second only to lung cancer in the UK (2). Worldwide, 1.36 million new CRC cases are diagnosed annually, and almost 700,000 deaths are estimated annually (1).

Expression of tissue factor (TF), the initiator of the extrinsic clotting pathway, is associated with a poor cancer prognosis in many solid tumours $(3,4)$. In CRC, expression

This article is freely accessible online.

Correspondence to: Hamish William Clouston, Institute of Cancer Sciences, The University of Manchester, 555 Wilmslow Road, Manchester M20 4GJ, U.K. Tel: +44 07870652859, E-mail: hamclou@hotmail.com

Key Words: Colorectal cancer, cancer stem cells, tissue factor. of TF is associated with higher disease stage (5), hepatic metastases (6) and reduced survival (7). TF has been reported to enhance the metastatic ability of pancreatic cancer cells in murine models (8). This effect may be related to the increased tumorigenicity and the resistance to anoikis that have been observed in TF-expressing cells (9-11). TF also increases primary tumour growth and proliferation (12-15).

Cancer stem cells (CSCs) are a small cellular subpopulation within a tumour, which possess the capacity to self-renew and generate the differentiated cancer cell lineages that comprise the tumour (16). CSCs have a crucial role in the development of metastases and treatment resistance $(17,18)$; therefore, they are potential therapeutic targets. In CRC, cells with CSC features have increased tumorigenicity when injected into mice models (19). Moreover, in xenogeneic mouse models of CRC, animals treated with chemotherapy and radiotherapy develop residual tumours enriched with CSCs $(20,21)$. These tumours have increased expression of stem cell markers and possess the ability to regenerate primary tumours (20-21). In vitro, CSC activity can be determined by using stem cell markers or the colonosphere assay. In CRC, aldehyde dehydrogenase (ALDH) is a well-established marker of CSCs $(22,21)$. On the other hand, in the colonosphere assay, CSCs are identified by their ability to resist anoikis and form clonal-derived spheres when cultured in suspension $(23,24)$.

The association of clinical effects of tumour TF expression and CSC activity has led to the hypothesis that TF may increase CSC activity. In squamous cell carcinoma (SCC) cells, TF expression correlates with the presence of the CSC marker CD133 and the ability of cells to form cancer spheres in vitro (25). Furthermore, treatment of SCC cells with CNTO 859, a TF-neutralising antibody, impairs their ability to form tumours when injected into mouse tails suggesting a negation of CSC activity (25). In breast cancer, high TF-expressing cells have increased tumour sphere-forming ability and higher expression of stem cell markers (26). The use of TF-targeting agents has been shown promising in breast, lung, and ovarian cancer therapy (27). In CRC, the link between TF and CSC activity has not been determined yet. The aim of this study was to determine the effect of TF on CSC activity in CRC. 


\section{Materials and methods}

Cell lines and culture. Human CRC cell lines DLD-1 and SW620 [American Type Culture Collection (ATCC), Rockville, MD, USA] were used for all assays. 293T cell line (ATCC) was used for the production of lentiviral particles. DLD-1 cells were maintained in McCoy's 5A (modified) medium supplemented with $10 \%$ heatinactivated foetal bovine serum (FBS) (Thermo Fisher Scientific, Waltham, MA, USA), $100 \mathrm{U} / \mathrm{ml}$ penicillin sodium and $100 \mathrm{mg} / \mathrm{ml}$ streptomycin sulphate. SW620 and 293T cells were maintained in Dulbecco's modified Eagle's medium (DMEM) supplemented with $10 \%$ heat-inactivated FBS (Thermo Fisher Scientific), $100 \mathrm{U} / \mathrm{ml}$ penicillin sodium, $100 \mathrm{mg} / \mathrm{ml}$ streptomycin sulphate, and $2 \mathrm{mM} / \mathrm{l}$ GlutaMAX (Thermo Fisher Scientific). All cell lines were maintained in an atmosphere of $5 \% \mathrm{CO}_{2}$ at $37^{\circ} \mathrm{C}$.

Lentiviral particle preparation. For knockdown transfection, lentiviral particles harbouring small hairpin RNA (shRNA) encoding human TF DNA or control shRNA were acquired from Santa Cruz Biotechnology (Santa Cruz, CA, USA). For TF overexpression (TFOE), lentiviral particles were prepared using the Lenti-Pac ${ }^{\mathrm{TM}}$ HIV Expression Packaging Kit (GeneCopoeia, Rockville, MD, USA) and the TF open reading frame (ORF) clone EX-Q0306-Lv105-10 (GeneCopoeia). An empty vector control, EX-NEG-LV105 (GeneCopoeia) was used as negative control (NC). 293 T cells were seeded in 10-cm culture dishes at a density of $1.5 \times 10^{6}$. After $48 \mathrm{~h}, 2.5 \mu \mathrm{g}$ of the lentiviral ORF expression plasmid and $5 \mu \mathrm{l}$ of Lenti-Pac HIV mix (GeneCopoeia) were diluted in $200 \mu \mathrm{l}$ of Opti-MEM (Thermo Fisher Scientific). Afterwards, $15 \mu \mathrm{l}$ of EndoFectin Lenti (GeneCopoeia) pre-diluted in $200 \mu \mathrm{l}$ of OptiMEM were added to the plasmid mix. Following incubation at room temperature for $20 \mathrm{~min}$, the final solution was added to the culture dishes containing 293T cells. After $10 \mathrm{~h}$, medium was replaced with fresh supplemented with 1:500 TitreBoost (GeneCopoeia). After a 48-h incubation, medium containing lentiviral particles was centrifuged at $500 \times g$ for $10 \mathrm{~min}$, and supernatant was harvested following filtration through $0.45 \mu \mathrm{m}$ polyethersulfone low protein binding filters. Lentiviral particles were stored at $-80^{\circ} \mathrm{C}$ until required.

Cell transfection. DLD-1 and SW620 cells were seeded in a 12-well plate at a density of $2.5 \times 10^{4}$ cells per well. After $24 \mathrm{~h}$, the culture media was removed and replaced with $1 \mathrm{ml}$ of DMEM supplemented with $5 \%$ heat-inactivated FBS, $2 \mathrm{mM} / 1$ GlutaMAX and polybrene (Santa Cruz Biotechnology, CA, USA) at a final concentration of 8 $\mu \mathrm{g} / \mathrm{ml}$. A volume of $20 \mu \mathrm{l}$ or $1 \mathrm{ml}$ of lentiviral particles for TFKD or TFOE, respectively, and the corresponding negative controls were added for $8 \mathrm{~h}$. Medium was then replaced with fresh DMEM supplemented with $10 \%$ heat-inactivated FBS and GlutaMAX. After $48 \mathrm{~h}$, transfected cells were selected using $2 \mu \mathrm{g} / \mathrm{ml}$ puromycin dihydrochloride (Thermo Fisher Scientific).

Flow cytometry. DLD-1 and SW620 cells were suspended in $100 \mu \mathrm{l}$ of phosphate buffered saline (PBS) $\left(3.0 \times 10^{5}\right.$ cells $\left./ 100 \mu \mathrm{l}\right)$ and incubated with a mouse monoclonal antibody against human $\mathrm{TF}$ (dilution 1:25; Sekisui Diagnostics, Lexington, MA, USA) for $20 \mathrm{~min}$, at room temperature in the dark. The suspension was centrifuged at $800 \times g$ for 2 min before being washed twice with PBS and resuspended in $200 \mu \mathrm{l}$ of PBS. Goat anti-mouse IgG crossadsorbed secondary antibody APC conjugate (Thermo Fisher Scientific) was added at a dilution of 1:100 and the mixture was incubated at room temperature for $20 \mathrm{~min}$ in the dark. Unstained cells were used as negative control samples. After centrifugation at $800 \times$ $g$ for 2 min and two washes with PBS, pellet was resuspended in 400 $\mu \mathrm{l}$ of PBS and $5 \mu \mathrm{l}$ of 7 -aminoactinomycin D (7AAD, Thermo Fisher Scientific) was added as a cell viability marker. Staining with 7AAD was used for the exclusion of dead cells from the analysis, and it also allowed the comparison of cellular viability between different expressions of TF as a validation assay. Flow cytometry was carried out using a BD FACSCalibur with CellQuest Pro v6.0 software (BD Biosciences, Franklin Lakes, NJ, USA). Data were analysed using FlowJo v10.0 (FlowJo, LLC, Ashland, OR, USA).

ALDH activity assay. The ALDEFLUOR ${ }^{\mathrm{TM}}$ Kit (Stemcell Technologies, Vancouver, Canada) was used according to manufacturer's instructions, for the detection of cells with high ALDH activity. Briefly, $1.0 \times 10^{6}$ cells diluted in $1 \mathrm{ml}$ of assay buffer were placed in the "sample test" tube and $5 \mu \mathrm{l}$ of ALDEFLUOR reagent were added. Immediately, $500 \mu \mathrm{l}$ of the mixture were transferred to the "sample control" tube containing diethylaminobenzaldehyde, to inhibit ALDH enzyme. Both samples were incubated at $37^{\circ} \mathrm{C}$ for $30 \mathrm{~min}$. Following centrifugation at $800 \times g$ for $2 \mathrm{~min}$, the cell pellets were resuspended in $500 \mu \mathrm{l}$ of assay buffer and 5 $\mu \mathrm{l}$ of 7AAD were added as a cell viability marker. Samples were directly analyzed by flow cytometry.

Colonosphere assay. Non-adherent cell culture plates (Corning, New York, USA) were coated with $1.2 \%$ (w/v) poly-2-hydroxyehyl methacrylate (polyHEMA, Sigma, Dorset, UK) dissolved in $95 \%$ ethanol, and were dried at $60^{\circ} \mathrm{C}$. Cells were cultured in colonosphere media (DMEM/F12, Thermo Fisher Scientific) supplemented with B12 supplement (Thermo Fisher Scientific), and $20 \mathrm{mg} / \mathrm{ml}$ recombinant EGF (Abbexa, Cambridge UK). A single-cell suspension of DLD-1 and SW620 cells was prepared in PBS by enzymatic and mechanical separation, using $0.25 \%$ trypsin-EDTA solution and 10 passes with a $25-$ gauge needle respectively. The cells were seeded $\left(3.0 \times 10^{2} \mathrm{cells} / \mathrm{cm}^{2}\right)$ in a 6-well non-adherent plate, and were incubated in an atmosphere of 5\% $\mathrm{CO}_{2}$ at $37^{\circ} \mathrm{C}$. After 5 days, the number of colonospheres $>50 \mu \mathrm{m}$ were counted using a microscope fitted with a graticule at a $4 \times$ magnification. Colonosphere forming efficiency (CFE, \%) was calculated as follows: (number of colonospheres per well/number of cells seeded per well) $\times 100$. Three wells were used for each variable in each experiment and the experiments were replicated in triplicate.

Proliferation assay. To ensure that any effect on CFE was not secondary to an increase in cellular proliferation, a proliferation assay was performed. DLD- 1 and SW620 cells were plated $\left(1 \times 10^{4}\right.$ cells/180 1 l/well in the appropriate media), in a 96-well plate (black with clear, flat bottom). A volume of $180 \mu \mathrm{l}$ of phosphate buffered saline (PBS) was added to surrounding empty wells. The cells were adhered after a 6-h incubation at $37^{\circ} \mathrm{C}, 5 \% \mathrm{CO}_{2}$ and $20 \mu \mathrm{l}$ of PrestoBlue ${ }^{\mathrm{TM}}$ (Thermo Fisher Scientific) was added for a further one-hour incubation. The bottom read fluorescence (excitation $544 \mathrm{~nm}$, emission $610 \mathrm{~nm}$ ) was measured using a FLUOstar Omega microplate reader (BMG Labtech, Aylesbury, UK). This process was repeated at 24, 48, $72 \mathrm{~h}$ for DLD-1 cells and 24, 48, 72 and 96 h for SW620 cells. Six wells were used per each experimental condition and each experiment was repeated in triplicate.

Statistical analysis. The student's $t$-test or Mann-Whitney $U$-test was used for statistical analysis depending on the data distribution. All $p$-values $<0.05$ were considered significant. All results are quoted as the mean \pm standard error of the mean (SEM) and are the result of three independent experiments. 


\section{Results}

Cell lines with intrinsically high TF expression were associated with decreased cancer stem cell activity. DLD-1 wild type (WT) cells were confirmed to intrinsically express higher levels of TF compared to SW620 WT cells $(p<0.05)$ (Figure 1A). CSC activity was compared between both cell lines. The intrinsically high TF expressing cell line, DLD-1, had a lower CFE $(p<0.01)$ (Figure 1B) and ALDH activity $(p=0.02)$ (Figure 1C) than the intrinsically low TF expressing SW620 cell line. This infers possible reduced CSC activity with high TF expression. However, this difference in CSC activity may simply be a bystander effect due to other differences between the cell lines.

Knockdown of TF was associated with increased cancer stem cell activity. SW620 and DLD-1 cells were stably transfected with TF shRNA to reduce the expression of TF (Figure 2A and 2B). CSC activity of TFKD SW620 and DLD-1 cells was compared to their corresponding negative control cells, transfected with an empty vector. Consistent with findings in the WT cells, SW620 and DLD-1 TFKD cells were associated with increased CFE (SW620 $p=0.01$, DLD-1 $p=0.01$ ) (Figure 2C and D) and ALDH activity (SW620 $p<0.01$, DLD-1 $p=0.04$ ) (Figure $2 \mathrm{E}$ and $\mathrm{F}$ ) compared to the controls. Thus, suggesting that reduced TF expression is associated with increased CSC activity.

Overexpression of TF was associated with decreased cancer stem cell activity. SW620 and DLD-1 cells were stably transfected to overexpress TF (Figure $3 \mathrm{~A}$ and $\mathrm{B}$ ). Subsequently, their CSC activity was compared to negative control. In line with the finding that TFKD increased CSC activity, TFOE was associated with decreased CFE $(p=0.006)$ (Figure 3D) and ALDH activity $(p=0.001)$ (Figure $3 F)$ in DLD-1 cells compared to their negative control. However, no difference was observed either in CFE $(p=0.4)$ (Figure 3C) or in ALDH activity $(p=0.4)$ (Figure $3 \mathrm{E}$ ) between TFOE SW620 cells and their negative control.

Expression of TF did not affect cellular viability. Comparison of CFE and ALDH activity in the WT and the transfected cells suggested that TF inhibits CSC activity. CSC activity assays, particularly the colonosphere assay, may be influenced by any detrimental impact on cellular viability which may be brought upon by the knockdown or overexpression of TF in SW620 and DLD-1 cells (28). Therefore, a viability assay was performed to quantify any differences. Results demonstrated that neither TFKD nor TFOE affected cellular viability in either SW620 or DLD-1 cells (Transfected Cell line compared to their negative control SW620: TFKD $p=0.7$, DLD-1 TFKD $p=0.8$, SW620 TFOE $p=0.5$, and DLD-1 TFOE $p=0.8$ ) (Figure 4).
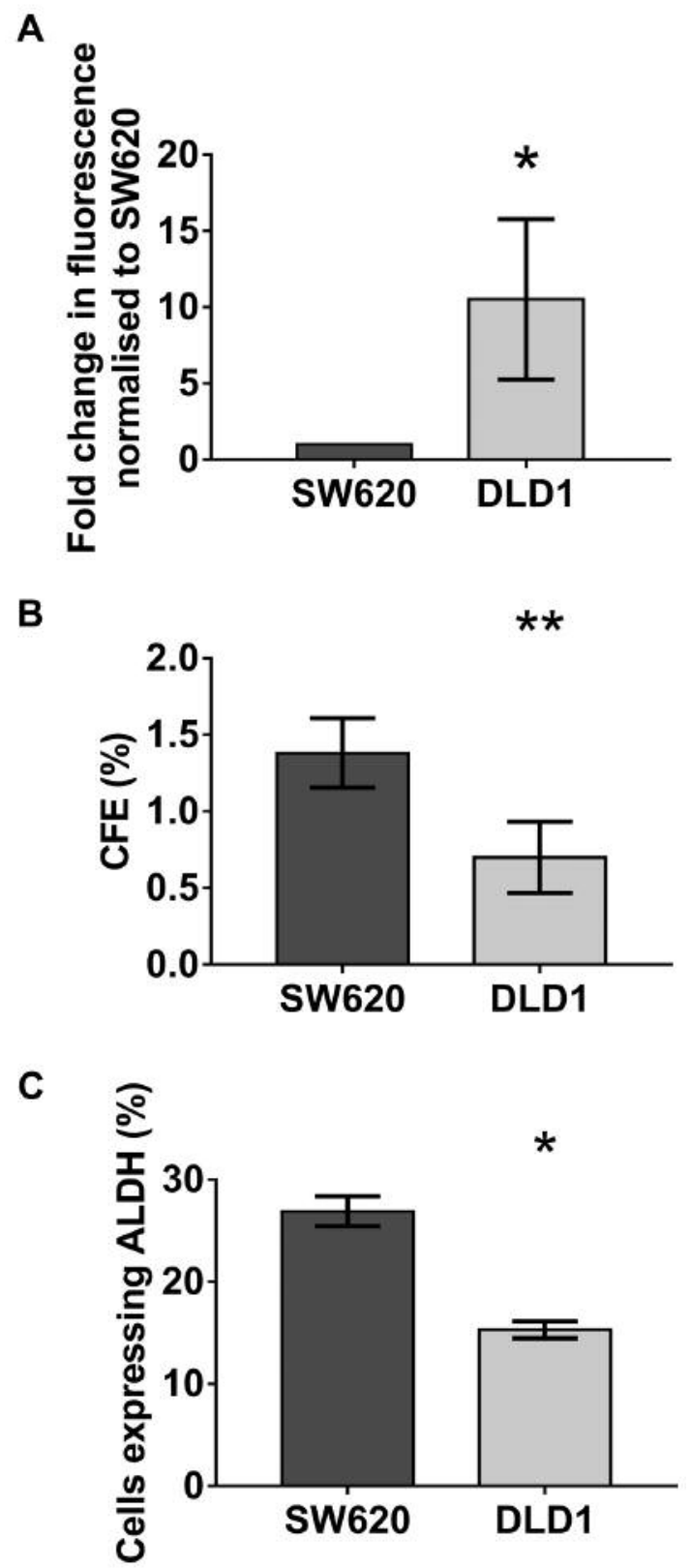

Figure 1. Cancer stem cell activity in wild-type cells. A: Tissue factor expression was assessed in wild type (WT) SW620 and DLD-1 cells using flow cytometry. DLD-1 cells had almost an 11-fold increase in TF expression compared to SW620 cells $(10.5 \pm 5.23, p<0.05)$. Data are presented as mean fold change in fluorescence normalised to SW620 cell line \pm SEM. B: DLD1 and SW620 cells were seeded in non-adherent conditions. After 5 days the number of colonospheres formed were counted and the colonosphere forming efficiency (CFE) was calculated [CFE\%=(number of colonospheres per well/number of cells seeded per well) $\times 100]$. CFE was decreased in DLD-1 cells compared to SW620 cells $(0.70 \pm 0.13 \%$ vs. $1.38 \pm 0.23 \%$, p<0.01). Data are presented as mean CFE $\pm S E M . C$ : Aldehyde dehydrogenase (ALDH) expression was quantified in both cell lines by flow cytometry using the ALDEFLUOR assay kit. ALDH activity was lower in DLD-1 cells compared to SW620 cells $(15.3 \pm 0.9 \%$ vs. $26.9 \pm 1.4 \%, p=0.02)$. Data are presented as mean percentage of cells expressing ALDH $\pm S E M$. Statistical analysis using the unpaired t-test, ${ }^{*} p<0.05$, **p<0.01. 

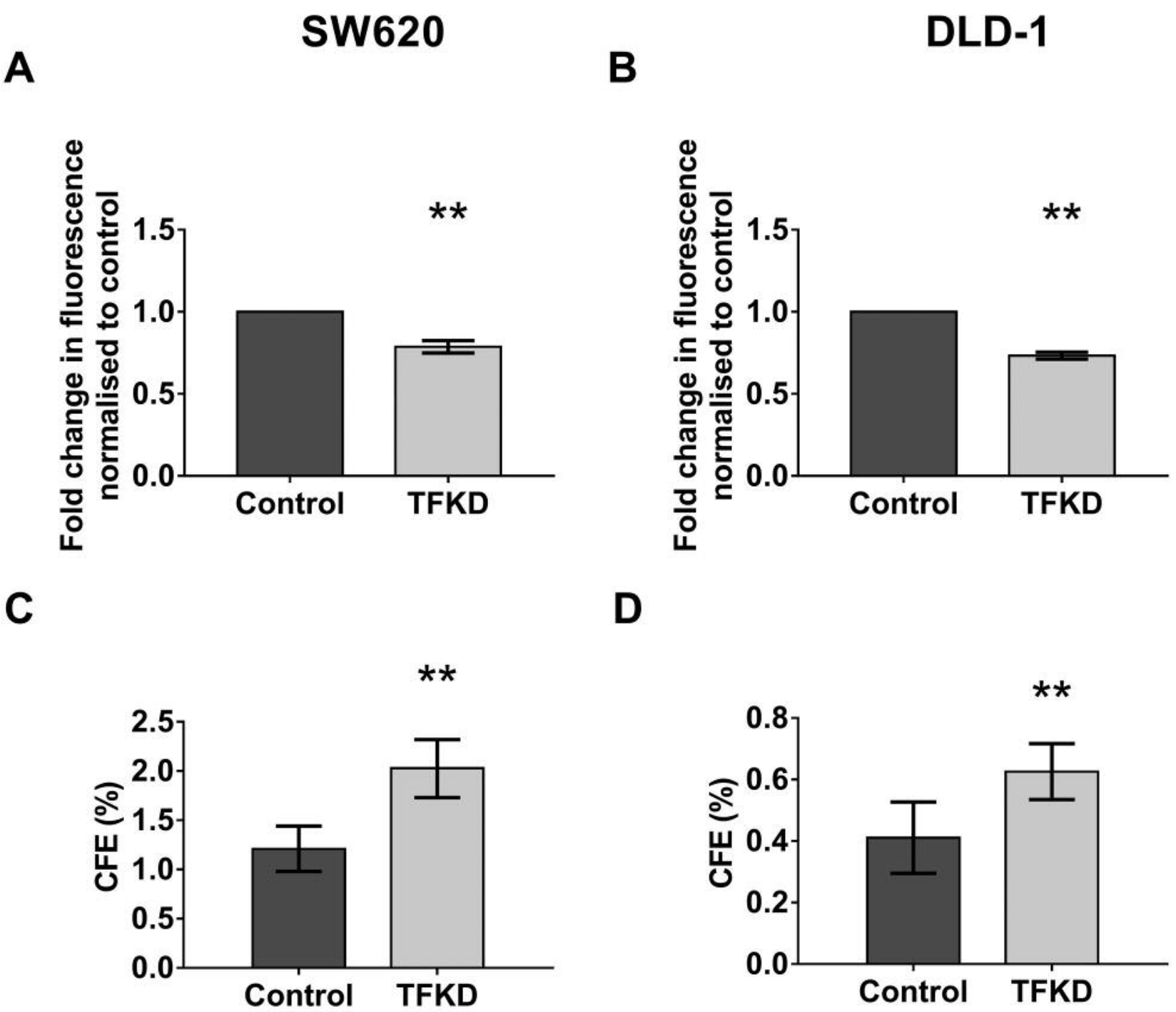

Figure 2. Tissue factor knockdown increased stem cell activity. A, B: Tissue factor expression was quantified in the SW620 and DLD-1 cell lines following lentiviral knockdown, using flow cytometry. Successful tissue factor knockdown (TFKD) was confirmed in both cell lines. Data are presented as mean fold change in fluorescence normalised to negative control \pm SEM. C, D: SW620 and DLD-1 TFKD cells were seeded in nonadherent conditions along with their corresponding negative controls. After 5 days, the number of colonospheres were counted and the colonosphere forming efficiency (CFE) was calculated (CFE\%=[number of colonospheres per well/number of cells seeded per well] $\times 100)$. TFKD was associated with an increase in CFE in both SW620 (2.03 $\pm 0.29 \% \mathrm{vs.} 1.21 \pm 0.23 \%, p=0.01)$ and DLD-1 $(0.68 \pm 0.9 \%$ vs. $0.41 \pm 0.12 \%$, $p=0.01)$ cells compared to their negative controls. Data presented as mean CFE \pm SEM. E, F: ALDH expression was quantified in SW620 and DLD-1 TFKD cells and compared with their respective negative controls by flow cytometry using the ALDEFLUOR assay kit. TFKD was associated with an increase in ALDH activity in SW620 (1.31 \pm 0.04 -fold change, $p<0.001)$ and DLD-1 (1.63 \pm 0.14 -fold change, $p=0.04)$ cells compared to their negative controls. Data presented as mean fold change in ALDH activity normalised to negative control \pm SEM. Statistical analysis using the unpaired t-test; *p<0.05;**p<0.01.

TF overexpression may increase proliferation. To ensure that the colonosphere assay was not affected by any change in proliferation resulting from TF expression, the effect of TF on cellular proliferation was determined. Minor differences in proliferation were observed in SW620 TFKD (decreased proliferation at $24 \mathrm{~h} p=0.02$, this difference disappeared by $48 \mathrm{~h} p=0.4)$ and DLD-1 TFOE increased proliferation at
$24 \mathrm{~h} p=0.01$, this difference disappeared by $48 \mathrm{~h} p=0.5$ ) compared to their negative controls (Figures 5A and D). No differences in proliferation were observed in the DLD-1 TFKD cells compared to their negative controls at any time point $(p>0.4)$ (Figure 5B). However, SW620 TFOE cells demonstrated increased proliferation at $72 \mathrm{~h}(p<0.0001)$, which persisted up to $96 \mathrm{~h}(p=0.01)$ (Figure 5C). This 


\section{SW620}

A

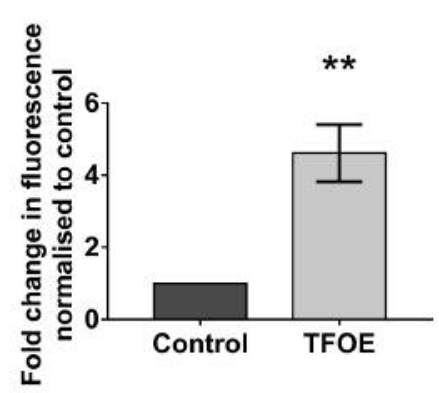

C

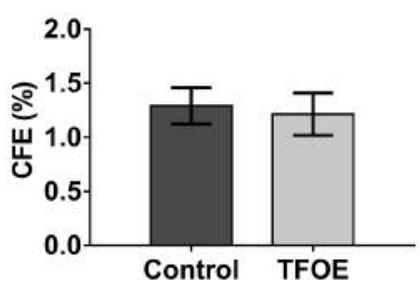

E

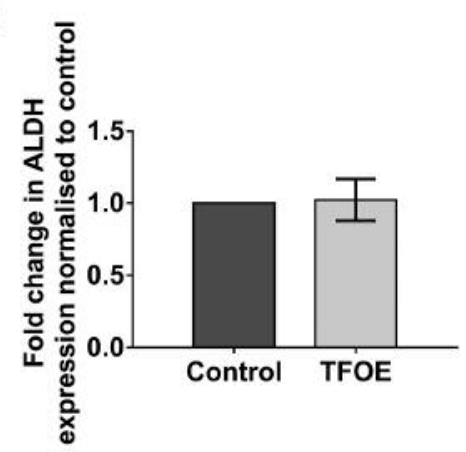

B

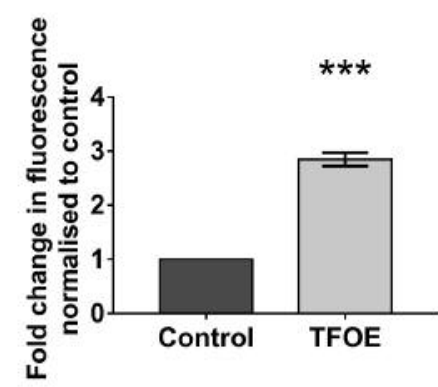

D

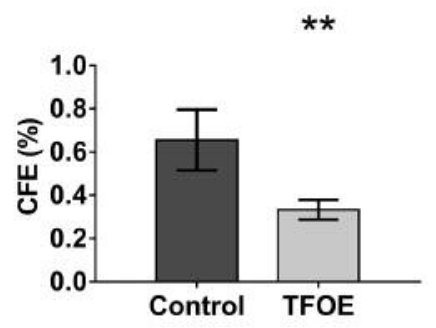

F

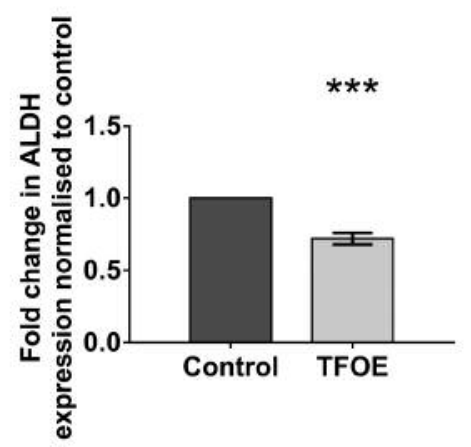

Figure 3. Tissue factor overexpression (TFOE) decreased stem cell activity. A, B: TF expression was quantified in the SW620 and DLD-1 cell lines following lentiviral over-expression, using flow cytometry. Successful (TFOE) was confirmed in both cell lines compared to their negative controls. Data are presented as mean fold change in fluorescence normalised to negative control \pm SEM. C, D: SW620 and DLD-1 TFOE cells were seeded in non-adherent conditions along with their corresponding negative controls. After 5 days the number of colonospheres formed were counted and the colonosphere forming efficiency (CFE) was calculated (CFE\%=[number of colonospheres per well/number of cells seeded per well] $\times 100)$. TFOE was associated with a decrease in CFE in DLD-1 (0.33 $\pm 0.05 \%$ vs. $0.66 \pm 0.14 \%$, $p=0.006)$ but not the $S W 620(1.21 \pm 0.23 \%$ vs. $1.29 \pm 0.17, p=0.4)$ cells compared to their negative controls. Data are presented as mean CFE \pm SEM. E, F: ALDH expression was quantified in SW620 and DLD-1 TFOE cells and compared with their respective negative controls by flow cytometry using the ALDEFLUOR assay kit. TFOE was associated with a significant decrease in ALDH activity in DLD-1 (0.72 \pm 0.04 fold change, $p=0.001)$ but not $S W 620(0.81 \pm 1.00$-fold change, $p=0.4)$ cells compared to their negative controls. Data are presented as mean fold change in ALDH activity normalised to negative control \pm SEM. Statistical analysis using the unpaired $t$-test; $* * p<0.01 ; * * * p<0.0001$.

increased proliferation might explain why there was no reduction in CFE in these cells compared to their negative controls. Since SW620 TFOE cells proliferate more rapidly, any negative effect of TF expression may be masked by the increasing proliferation. The finding that TF increases proliferation in the SW620 is consistent with previous research (29).

\section{Discussion}

In this study, the CSC activity of CRC cells was investigated in vitro by using the colonosphere assay and the evaluation of ALDH activity, which is a biomarker of cancer precursor cells. Results demonstrated that the expression level of TF was inversely correlated with CSC activity. High TF-expressing cell 
A

SW620

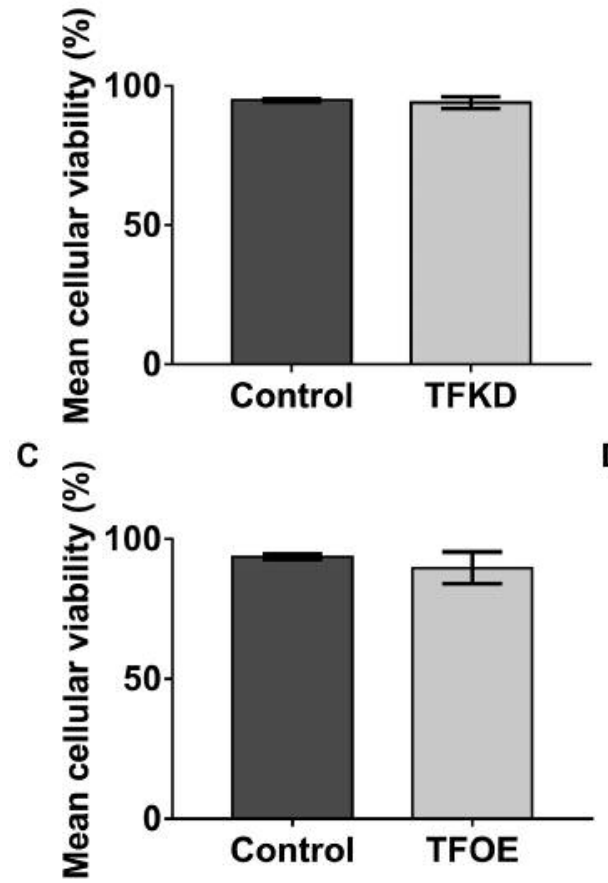

B DLD-1

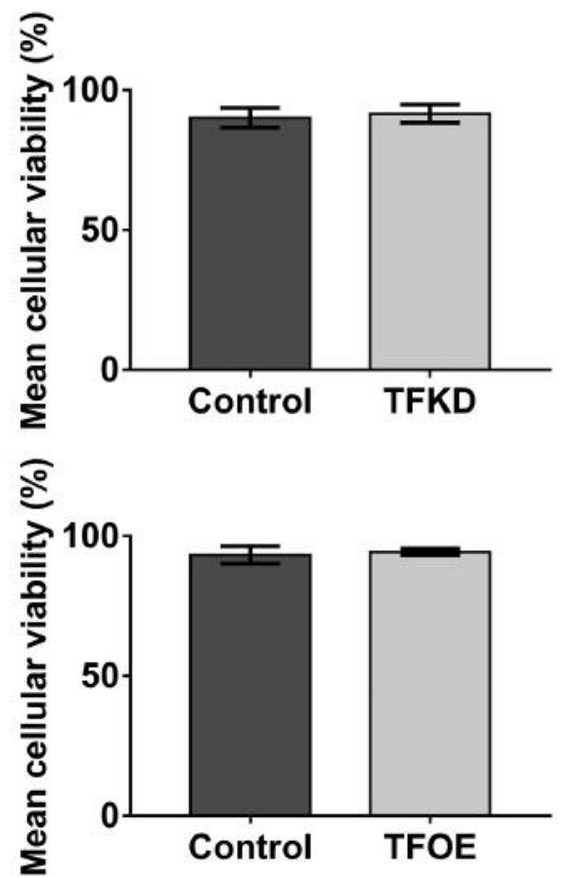

Figure 4. The effect of tissue factor knockdown (TFKD) and TF overexpression (TFOE) on cellular viability. Staining with 7AAD was used as a liveldead discriminatory to ensure that the level of TF expression did not affect cellular viability. No effect was observed on cellular viability between

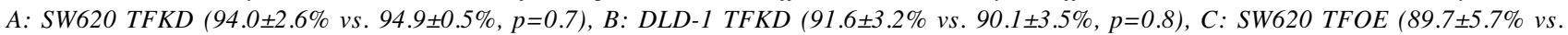
$93.7 \pm 0.9 \%, p=0.5)$ or D: DLD-1 TFOE $(94.4 \pm 1.2 \%$ vs. $93.3 \pm 0.1 \%, p=0.8)$ cells and their respective negative controls. Data presented as mean cellular viability $(\%) \pm$ SEM. Statistical analysis was performed using unpaired $t$-test.

line, DLD-1, had reduced CSC activity in comparison to the low TF-expressing cell line, SW620. This could simply be a bystander effect due to other differences between these cell lines. However, consistent with this finding, when the cell lines were transfected to knockdown TF, CSC activity was increased in both DLD-1 and SW620 cells. A consistent inverse relationship between TF expression and CSC activity was also seen following over expression of TF in the DLD-1 cell line. In the SW620 cell line there was no change in the CSC activity when TF expression was increased. This may be the result of increased proliferation, since, as demonstrated by the PrestoBlue proliferation assay, TFOE SW620 cells showed a significant increase in proliferation at $96 \mathrm{~h}$. Cell viability was not affected by either the knockdown or overexpression of TF in either cell line.

TF-targeted treatments have recently been proposed as a potential therapeutic approach against cancer (27). Therefore, the finding that TF expression is inversely related to CSC activity in CRC is important. Conversely to these results regarding $\mathrm{CRC}$, studies on other tumour types, including SCC, breast, ovarian and lung cancers, have shown that TF increases CSC activity $(27,25,26)$. Although our work is limited to in vitro experiments, it has demonstrated a consistent effect of TF expression across cell lines with the exception of SW620 TFOE cells. In the non-cancer stem cell population (haematological cell line) the expression of TF increases with differentiation away from the pluripotent stem cells(30). The difference between the effect of TF on CRC CSC and the SCC, breast and lung cancers may reflect the complexity of CRC stem cell control. The control of CSC activity in CRC cancer is multifactorial with complex interactions between many pathways. Signalling pathways that have been demonstrated to have a role in the control of CRC CSC activity include the Wnt, Notch, bone morphogenetic protein (BMP)/TGF- $\beta$, Hedgehog-Gli (HHGLI), epidermal growth factor receptor (EGFR)/mitogenactivated protein kinase (MAPK), NF- $x \mathrm{~B}$ and Akt/mTOR pathways (31). Some of these same pathways are influenced by TF expression, including Wnt (32) and AKT (33), whereas others, including MAPK and ERK, are implicated in the regulation of $\mathrm{TF}$ expression $(34,35)$. The unexpected effect of TF on CRC CSC activity in this study may be the result of interactions between these pathways. The determination of this interaction is beyond the scope of this study and further pathway analysis of the role of TF in CRC CSC is needed. The finding that TF inhibited CSC activity in CRC suggests 


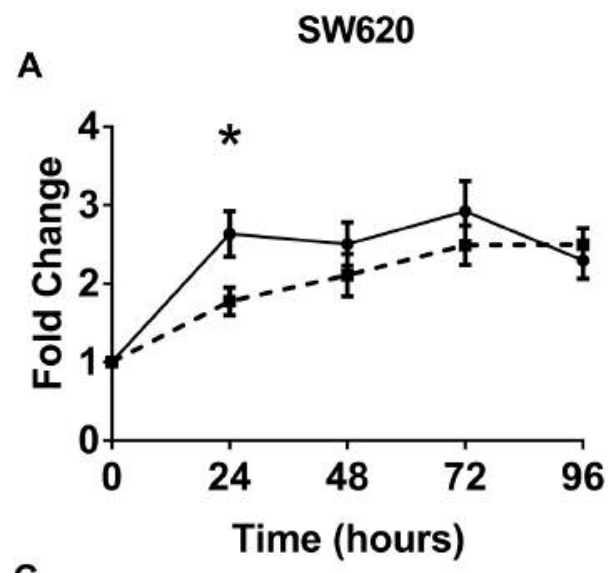

B

\section{DLD-1}

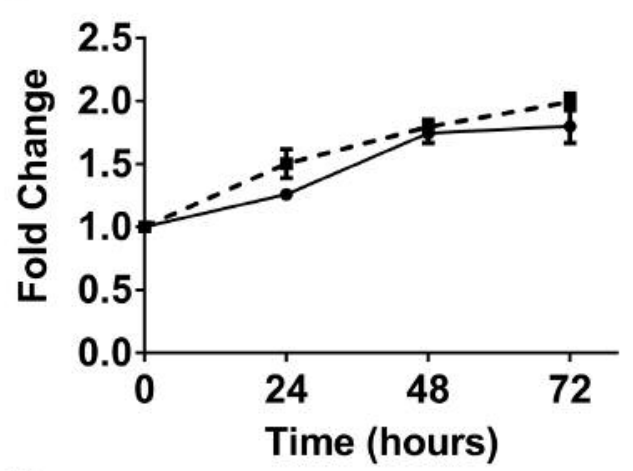

D

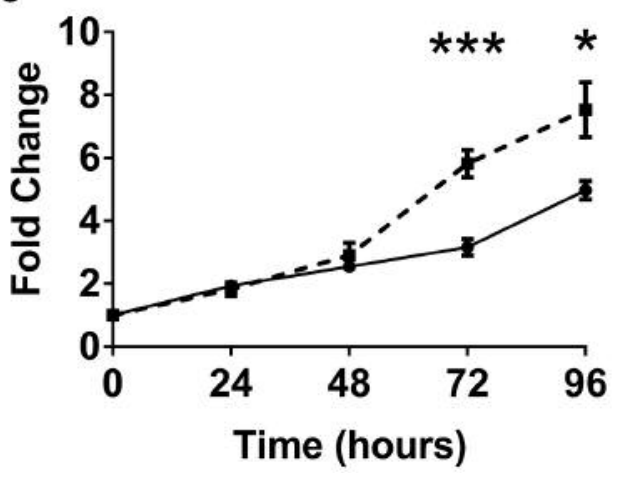

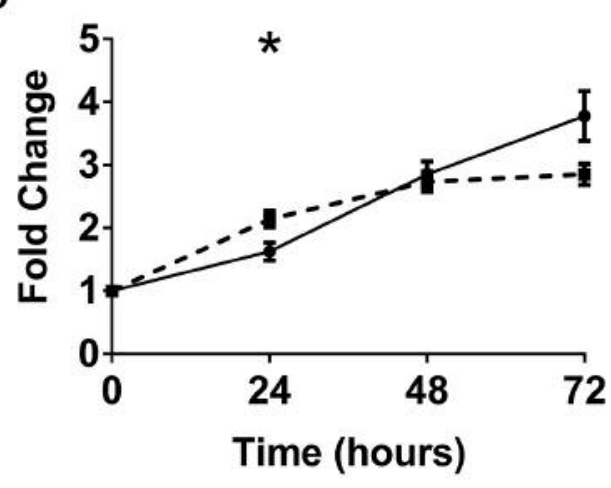

Figure 5. The effect of tissue factor (TF) expression on SW620 and DLD-1 cell proliferation was assessed using the PrestoBlue proliferation assay. A: SW620 TF knockdown (TFKD) cells were associated with decreased proliferation at 24 h compared to their negative controls (1.78 $\pm 0.18-f o l d$ change vs. 2.64 \pm 0.29 -fold change, $p=0.02$ ). This difference disappeared by $48 \mathrm{~h}$. B: DLD-1 TFKD cells were not associated with any difference in proliferation at any time point. C: SW620 TFOE cells were associated with increased proliferation at 72 h compared to their negative controls (5.82 \pm 0.43 -fold change vs. 3.17 \pm 0.27 -fold change, $p<0.0001)$. This difference in proliferation persisted at $96 \mathrm{~h}(7.53 \pm 0.88$-fold change vs. $4.97 \pm 0.29$ fold change, $p=0.01)$. D: DLD-1 TFOE cells were associated with increased proliferation at 24 compared to their negative controls $(2.14 \pm 0.13$ fold change vs. 1.63 \pm 0.14 -fold change, $p=0.01$ ). This difference in proliferation disappeared by 48 h. Data presented as mean fold change in fluorescence $\pm S E M$ normalised to time point $0 \mathrm{~h}$. Solid line $=$ negative control, broken line $=$ transfected cell line. Statistical analysis was performed using the unpaired t-test or Mann-Whitney $U$ - test, depending on the distribution of the data. $* p<0.05 ; * * *<<0.0001$.

that, unlike in breast and lung cancer treatments, targeting TF may be unsuccessful as an anticancer treatment. It may be that in CRC inhibition of TF could worsen cancer prognosis by increasing the activity of the treatment resistant tumour subgroup of CSCs.

\section{Conclusion}

This study is the first reporting the effect TF has on CRC CSCs. This study has demonstrated that TF inhibits the activity of CRC CSCs. The results suggest that unlike in other solid cancers, including breast and lung, anti-cancer treatments targeting TF may not have a therapeutic role.

\section{Acknowledgements}

This work was supported by a NIHR Clinical Scientist Award (CC Kirwan) and Royal College of Surgeons Fellowship (PA Rees).

\section{References}

1 Ervik M, Lam F, Ferlay J, Mery L, Soerjomataram I, and Bray F: Cancer Today. Lyon, France: International Agency for Research on Cancer, Lyon, France, 2016. http://gco.iarc.fr/today (Accessed 10/01/2017), 2016.

2 Cancer Research UK. Cancer mortality for common cancers. http://www.cancerresearchuk.org/health-professional/cancerstatistics/mortality/common-cancers-compared\#heading-Zero (Accessed 03/05/2017).

3 Ueno T, Toi M, Koike M, Nakamura S and Tominaga T: Tissue factor expression in breast cancer tissues: its correlation with prognosis and plasma concentration. Br J Cancer 83: 164, 2000.

4 Khorana AA, Ahrendt SA, Ryan CK, Francis CW, Hruban RH, $\mathrm{Hu}$ YC, Hostetter G, Harvey J and Taubman MB: Tissue factor expression, angiogenesis, and thrombosis in pancreatic cancer. Clin Cancer Res 13: 2870-2875, 2007.

5 Nakasaki T, Wada H, Shigemori C, Miki C, Gabazza EC, Nobori T, Nakamura S and Shiku H: Expression of tissue factor and 
vascular endothelial growth factor is associated with angiogenesis in colorectal cancer. Am J Hematol 69: 247-254, 2002.

6 Shigemori C, Wada H, Matsumoto K, Shiku H, Nakamura S and Suzuki H: Tissue factor expression and metastatic potential of colorectal cancer. Thromb Haemost 80: 894-898, 1998.

7 Seto S, Onodera H, Kaido T, Yoshikawa A, Ishigami S, Arii S and Imamura M: Tissue factor expression in human colorectal carcinoma: correlation with hepatic metastasis and impact on prognosis. Cancer 88: 295-301, 2000.

8 Saito Y, Hashimoto Y, Kuroda J, Yasunaga M, Koga Y, Takahashi A and Matsumura Y: The inhibition of pancreatic cancer invasion-metastasis cascade in both cellular signal and blood coagulation cascade of tissue factor by its neutralisation antibody. Eur J Cancer 47: 2230-2239, 2011.

9 Milsom C, Magnus N, Meehan B, Al-Nedawi K, Garnier D and Rak J: Tissue factor and cancer stem cells: is there a linkage? Arterioscler Thromb Vasc Biol 29: 2005-2014, 2009.

10 Versteeg HH, Spek CA, Richel DJ and Peppelenbosch MP: Coagulation factors VIIa and Xa inhibit apoptosis and anoikis. Oncogene 23: 410-417, 2004.

11 Sorensen BB, Rao LV, Tornehave D, Gammeltoft S and Petersen LC: Antiapoptotic effect of coagulation factor VIIa. Blood 102: 1708-1715, 2003.

12 Ruf W, Disse J, Carneiro-Lobo TC, Yokota N and Schaffner F: Tissue Factor and Cell Signalling in Cancer Progression and Thrombosis. J Thromb Haemost 9: 306-315, 2011.

13 de Oliveira Ada S, Lima LG, Mariano-Oliveira A, Machado DE, Nasciutti LE, Andersen JF, Petersen LC, Francischetti IM and Monteiro RQ: Inhibition of tissue factor by ixolaris reduces primary tumor growth and experimental metastasis in a murine model of melanoma. Thromb Res 130: e163-170, 2012.

14 Hembrough TA, Swartz GM, Papathanassiu A, Vlasuk GP, Rote WE, Green SJ and Pribluda VS: Tissue factor/factor VIIa inhibitors block angiogenesis and tumor growth through a nonhemostatic mechanism. Cancer Res 63: 2997-3000, 2003.

15 Yu JL, May L, Lhotak V, Shahrzad S, Shirasawa S, Weitz JI, Coomber BL, Mackman N and Rak JW: Oncogenic events regulate tissue factor expression in colorectal cancer cells: implications for tumor progression and angiogenesis. Blood 105: 1734-1741, 2005.

16 Reya T, Morrison SJ, Clarke MF and Weissman IL: Stem cells, cancer, and cancer stem cells. Nature 414: 105, 2001.

17 Dave B, Mittal V, Tan NM and Chang JC: Epithelialmesenchymal transition, cancer stem cells and treatment resistance. Breast Cancer Res 14: 202, 2012.

18 Hermann PC, Huber SL, Herrler T, Aicher A, Ellwart JW, Guba M, Bruns CJ and Heeschen C: Distinct populations of cancer stem cells determine tumor growth and metastatic activity in human pancreatic cancer. Cell Stem Cell 1: 313-323, 2007.

19 Ricci-Vitiani L, Fabrizi E, Palio E and De Maria R: Colon cancer stem cells. Journal of Molecular Medicine 87: 1097-1104, 2009.

20 Dylla SJ, Beviglia L, Park I-K, Chartier C, Raval J, Ngan L, Pickell K, Aguilar J, Lazetic S and Smith-Berdan S: Colorectal cancer stem cells are enriched in xenogeneic tumors following chemotherapy. PloS one 3: e2428, 2008.

21 Arcaroli JJ, Powell RW, Varella-Garcia M, McManus M, Tan AC, Quackenbush KS, Pitts TM, Gao D, Spreafico A, Dasari A, Touban BM and Messersmith WA: ALDH+ tumor-initiating cells exhibiting gain in NOTCH1 gene copy number have enhanced regrowth sensitivity to a gamma-secretase inhibitor and irinotecan in colorectal cancer. Mol Oncol 6: 370-381, 2012.

22 Huang E, Hynes M, Zhang T, Ginestier C, Dontu G, Appelman $\mathrm{H}$, Fields J, Wicha M and Boman B: Aldehyde dehydrogenase 1 is a marker for normal and malignant human colonic stem cells (SC) and tracks SC overpopulation during colon tumorigenesis. Cancer Res 69: 3382-3389, 2009.

23 Shaw FL, Harrison H, Spence K, Ablett MP, Simoes BM, Farnie $\mathrm{G}$ and Clarke RB: A detailed mammosphere assay protocol for the quantification of breast stem cell activity. J Mammary Gland Biol Neoplasia 17: 111-117, 2012.

24 Shaheen S, Ahmed M, Lorenzi F and Nateri AS: Spheroid-formation (colonosphere) assay for in vitro assessment and expansion of stem cells in colon cancer. Stem Cell Rev 12: 492-499, 2016.

25 Milsom C, Anderson GM, Weitz JI and Rak J: Elevated tissue factor procoagulant activity in CD133-positive cancer cells. J Thromb Haemost 5: 2550-2552, 2007.

26 Shaker H, Harrison H, Clarke R, Landberg G, Bundred NJ, Versteeg HH and Kirwan CC: Tissue factor promotes breast cancer stem cell activity in vitro. Oncotarget 8: 25915, 2017.

$27 \mathrm{Hu} \mathrm{Z,} \mathrm{Xu} \mathrm{J,} \mathrm{Cheng} \mathrm{J,} \mathrm{McMichael} \mathrm{E,} \mathrm{Yu} \mathrm{L} \mathrm{and} \mathrm{Carson} \mathrm{III} \mathrm{WE:}$ Targeting tissue factor as a novel therapeutic oncotarget for eradication of cancer stem cells isolated from tumor cell lines, tumor xenografts and patients of breast, lung and ovarian cancer. Oncotarget 8: 1481, 2017.

28 van den Berg YW, Osanto S, Reitsma PH and Versteeg HH: The relationship between tissue factor and cancer progression: insights from bench and bedside. Blood 119: 924-932, 2012.

$29 \mathrm{Hu} \mathrm{L}$, Xia L, Zhou H, Wu B, Mu Y, Wu Y and Yan J: TF/FVIIa/PAR2 promotes cell proliferation and migration via PKCalpha and ERK-dependent c-Jun/AP-1 pathway in colon cancer cell line SW620. Tumour Biol 34: 2573-2581, 2013.

$30 \mathrm{Yu}$ Y-H, Wu D-S, Huang F-F, Zhang Z, Liu L-X, Zhang J, Zhan H-E, Peng M-Y, Zeng H and Chen F-P: MicroRNA-20b and ERK1/2 pathway independently regulate the expression of tissue factor in hematopoietic and trophoblastic differentiation of human embryonic stem cells. Stem Cell Res Ther 4: 121-121, 2013.

31 Pan T, Xu J and Zhu Y: Self-renewal molecular mechanisms of colorectal cancer stem cells. Int J Mol Med 39: 9-20, 2017.

32 Wang Y, Sang A, Zhu M, Zhang G, Guan H, Ji M and Chen H: Tissue factor induces VEGF expression via activation of the $\mathrm{Wnt} / \beta$-catenin signaling pathway in ARPE-19 cells. Mol Vis 22: 886-897, 2016.

33 Arderiu G, Pena E, Aledo R and Badimon L: Tissue factor-Akt signaling triggers microvessel formation. J Thromb Haemost 10: 1895-1905, 2012.

34 Bohgaki M, Atsumi T, Yamashita Y, Yasuda S, Sakai Y, Furusaki A, Bohgaki T, Amengual O, Amasaki Y and Koike T: The p38 mitogen-activated protein kinase (MAPK) pathway mediates induction of the tissue factor gene in monocytes stimulated with human monoclonal anti- $\beta 2$ Glycoprotein $I$ antibodies. Int Immunol 16: 1633-1641, 2004.

$35 \mathrm{Hu}$ C, Huang L, Gest C, Xi X, Janin A, Soria C, Li H and Lu $\mathrm{H}$ : Opposite regulation by PI3K/Akt and MAPK/ERK pathways of tissue factor expression, cell-associated procoagulant activity and invasiveness in MDA-MB-231 cells. J Hematol Oncol 5: 16$16,2012$.

Received February 20, 2018

Revised March 26, 2018

Accepted March 30, 2018 